\title{
Nonconscious priming of communication
}

\author{
Martin J. Pickering, Janet F. McLean, Marina Krayeva
}

This is the accepted manuscript (C) 2015, Elsevier.

Licensed under the Creative Commons Attribution-NonCommercialNoDerivatives 4.0 International http://creativecommons.org/licenses/by-nc-nd/4.0/ (cc) EY-NG-ND

The published article is available from doi: http://dx.doi.org/10.1016/j.jesp.2014.12.007 
Nonconscious priming of communication

Martin J. Pickering, Janet F. McLean, and Marina Krayeva

University of Edinburgh

Martin J. Pickering, Department of Psychology, University of Edinburgh; Janet F.

McLean, Department of Psychology, University of Edinburgh ${ }^{1}$; Marina Kraeva, Department of Psychology, University of Edinburgh.

We acknowledge support of ESRC grant RES-062-23-0376.

Correspondence concerning this article should be addressed to Martin Pickering, Department of Psychology, University of Edinburgh, 7 George Square, Edinburgh EH8 9JZ, United Kingdom. Email: martin.pickering@ed.ac.uk, Tel: +44 1316503447

\footnotetext{
${ }^{1}$ Present address: Psychology, Abertay University.
} 


\begin{abstract}
This study investigated whether nonconscious priming can affect the communicative quality of narratives. In two experiments, narrators were primed with words associated with helpfulness or unhelpfulness, and then, in an apparently unrelated task, read and retold a short story to addressees. In Experiment 1, the narrator provided a spoken description, and we also manipulated whether the narrator retold the story to the addressee or to a microphone. In Experiment 2, the narrator provided a written description. In both experiments, narrators primed with helpful words took longer to read the story and provided retellings that were rated to be higher quality than narrators primed with unhelpful words. We propose that priming the concept of helpfulness influences the processes involved in message construction.
\end{abstract}

Keywords: communication; nonconscious priming; narrator; addressee

Word count: 2357 
Highlights

- Two priming experiments investigated reading and communicating stories

- Priming narrators with helpfulness-related words lengthened reading time

- Priming narrators with helpfulness-related words improved retelling

- Activation of the helpfulness concept influences message construction 
Nonconscious priming of communication

People do not speak into a vacuum, but rather produce utterances for their addressees (e.g., H.H. Clark, 1996). In general, they care about the quality and accuracy of their utterances for their audience. But does their motivation to be communicatively effective vary? And to what extent can the incidental activation of social knowledge affect communication?

Communicative effectiveness is influenced by characteristics of the audience. For example, people speak differently to children versus adults (Glucksberg, Krauss \& Weisberg, 1966), native versus non-native speakers (Bortfeld \& Brennan, 1997), or experts versus novices in a particular domain (e.g., Isaacs \& Clark, 1987). They also produce clearer referring expressions when they believe that their addressee would not be able to identify a stimulus (Fussell \& Krauss, 1992). In addition, they sometimes make sure that their utterances are not unnecessarily ambiguous, for example reverting to a longer and clearer description of a novel object when describing it to a new addressee (e.g., Brennan \& Clark, 1996) or producing syntactically disambiguated utterances (Haywood, Pickering, \& Branigan, 2005). However, speakers are not always helpful in this way (e.g., Ferreira \& Dell, 2000; Horton \& Keysar, 1996). Accounts of when speakers are helpful tend to consider the effects of characteristics of the stimuli (what is being described), knowledge of addressees, and processing limitations - factors which tend to be relevant to cognitive theories of language use.

This research indicates that communicative effectiveness depends on social context. But it does not demonstrate what causes speakers to emphasize communicative effectiveness. Such choices can of course be under the conscious control of the speaker. For example, speakers modify their utterances when they become aware of the need to be more comprehensible. Thus, Horton and Gerrig (2002) had speakers describe arrays of picture cards to matchers who had 
previously discussed some of the cards with the speakers. The speakers described these cards differently than cards that they had not already discussed and became more aware of the importance of such adjustments as the experiment went on. They suggest that the decision about whether to emphasize intelligibility is a deliberate, conscious act that serves the goal of increasing the comprehensibility of an act of communication. This is compatible with traditional models of human behavior, which claim that it is guided by explicit goals only (Bandura, 1986; Deci \& Ryan, 1985).

But could speakers' choice of utterances be affected by implicit factors? Research in social psychology suggests that goals are not merely consciously selected but can be activated outside of awareness (Bargh, Gollwitzer, Lee-Chai, Barndollar, \& Trötschel, 2001; see Moskowitz, Li, \& Kirk, 2004). Bargh et al. found that priming people to perform well or to cooperate had similar effects to explicitly providing them with that goal, and argued that priming specifically activated a goal concept (e.g., noting that the strength of the activation increased over time if the goal was not fulfilled). The priming manipulation involved participants unscrambling sentences involving words related to the relevant concept (e.g., helpfulness), and participants were unaware of the manipulation. Another study primed participants with the goal of earning money and showed that they then worked faster on an initial task so as to get to a second task that afforded the chance to earn money (Aarts, Gollwitzer, \& Hassin, 2004) Similarly, priming the concept of egalitarianism has been shown to lead participants to implicitly inhibit social stereotypes (e.g., Moskowitz, Gollwitzer, Wasel, \& Schaal, 1999; Moskowitz \& Li, 2011). Even 18-month old infants engage in more helpful behavior following an affiliative prime (two dolls facing each other) than otherwise (Over \& Carpenter, 2009). 
Many studies have found that unconscious goal pursuit produces the same outcomes as conscious goal pursuit (Chartrand \& Bargh, 1996; Dijksterhuis \& Aarts, 2010; Dijksterhuis, Chartrand, \& Aarts, 2007). However, there appear to be many mediators to effects of priming on goal pursuit (e.g., Locke \& Latham, 2006). There is evidence that priming is enhanced when the primes are associated with positive affect, suggesting that priming stimuli are integrated with reward cues to motivate effortful behavior (Aarts, Custers, \& Marien, 2008). However, the effects of priming also appear to be moderated by personality characteristics, such as relationship orientation (Chen, Lee-Chai, \& Bargh, 2001; M. Clark \& Mills, 1979) and need for structure (Thompson, Roman, Moskowitz, Chaiken, \& Bargh, 1994).

But few of these studies directly relate to communication and its effectiveness. This situation is perhaps surprising, given that the ways in which people communicate information to their audience can differ greatly in helpfulness. They can carefully work out which details are useful or relevant and carefully frame their utterances, or they can produce limited, barely relevant, or ambiguous descriptions. Moreover, communication depends on norms such as the Gricean maxims (Grice, 1975): Among other things, speakers are expected to convey the appropriate amount of information, to make their contribution relevant, and to avoid obscurity or ambiguity. But the application of these maxims depends on the context. For example, the appropriate information depends on what is required for current purposes. We might expect an assessment of appropriateness and perspicuity to be particularly dependent on the speaker's goals, which could then in turn be strongly affected by implicit factors.

Theories of how people produce language assume that they first construct the message that they wish to convey, then convert that message into linguistic representations (concerned with grammar and sound), and finally articulate in a spoken or written form (see Levelt, 1989). 
At the first (conceptualization) stage, speakers or writers make a series of decisions about how much information to convey and the extent to which they should emphasize perspicuity. When their task is to retell a story, they have to decide how much attention to pay to understanding and remembering its details. If they are particularly concerned about detailed or accurate retelling, they will spend longer reading (and therefore assimilating) the story, and will therefore construct a more elaborate conceptual representation.

In this study we investigate whether nonconsciously priming the goal of helpfulness can lead to participants designing their utterances in a way that reflects their addressees' needs in a communication task. We predict that narrators that have been primed to be helpful will be more sensitive to the needs of their listener when retelling a story. They should take more time to read the story and should produce a higher-quality retelling. Conversely, narrators that have been primed to be unhelpful will not be sensitive to the needs of their listener. They should take less time to read the story and produce lower-quality retelling. Experiment 1 involved spoken narration, whereas Experiment 2 involved written narration (and did not include a real addressee). In addition, Experiment 1 manipulated whether the narrator retold the story to a present addressee (who was able to provide feedback) or via a microphone. One possibility is that an addressee highlights the importance of successful communication and hence that communicative goals should be more powerful in the presence of an addressee. If so, the priming manipulation should have a stronger effect in the present-addressee condition that the microphone condition. But it is also possible that participants are similarly aware of the need to communicate whether the addressee is present or not. If so, the priming manipulation should be unaffected by the presence of an addressee. 


\section{Experiment 1}

\section{Method}

Participants. Forty naïve participants (20 female) from the University of Edinburgh student community were paid to participate. All were native English speakers and reported having no reading or speaking difficulties.

Materials and procedure. Participants were paired with same-sex partners who they did not know and were randomly assigned the role of narrator or addressee. They were also randomly assigned to priming condition (helpful vs. unhelpful) and retelling condition (face-toface vs. microphone). The experimenter was blind to priming condition.

The experimenter explained that the experiment consisted of two unrelated short studies and that the first study investigated "psycholinguistic decision-making processes" and involved a word-search puzzle (as in Bargh et al., 2001). Each participant was presented with a puzzle and was given 5 minutes to complete the task. Each puzzle consisted of a $10 \times 10$ matrix of letters and a list of 13 words, which were hidden in the matrix (horizontally, vertically, or diagonally, in either direction). In the helpful condition, the narrator's puzzle contained eight words associated with helpfulness (assistance, cooperate, friend, help, mutual, satisfy, support, useful) and five neutral words (building, green, lamp, staple, tree). In the unhelpful condition, it contained eight words associated with unhelpfulness (delay, difficulty, hindrance, lazy, obstruct, selfish, stop, inhibit) and the same neutral words. The addressee's puzzle contained thirteen neutral words (banana, flower, magazine, pencil, plant, table, theatre, turtle, building, green, lamp, staple, tree). The narrator and addressee completed their word search puzzles at the same time and in the same room. 
Participants were told that the second task was a test of their language ability, and that it was the narrator's job to read a story and retell it to the addressee, who would then retell the story again. They were informed that only the addressee's retelling would be marked for quality, in terms of how much it matched the original story. The story was abridged from a story used in Ratcliff and McKoon (1988) and was presented on a single sheet. The addressee then left the room and the experimenter told the narrator to take as much time as he or she needed to understand the story. The time taken to read the story was recorded manually by the experimenter. The narrator was not aware of the recording. Once the narrator had finished reading, the experimenter told the narrator how to retell the story. In the face-to-face condition, the addressee returned to the room and listened to the story. The addressee was given no specific instructions about providing feedback. In the microphone condition, the narrator retold the story to a digital recording device (without the addressee being present). In this condition, once the story had been re-told, the addressee returned to the room. In both conditions, the addressee then retold the story. All the retellings were recorded and transcribed.

Both participants then filled in a brief questionnaire, which included general questions about the room and the experimenter, and more specific questions about what they thought the experiment was about and whether the two parts were related.

Story Ratings. Two independent raters who were unaware of the experimental manipulations rated the relationship between the original story and its retelling on a scale from 1 (very poor variant of the original) to 5 (very close to the original). The raters' reliability was .82 (intraclass correlation); we report their mean ratings.

\section{Results and Discussion}


Narrator Retelling. We conducted Prime (helpful vs. unhelpful) x Retelling (face-toface vs. microphone) between-participants ANOVAs on the time the narrator spent reading the story and the quality of the narrator's story (see Tables 1 and 2). Analyses on reading time were carried out on square-root transformed data to correct for violations of the homogeneity of variance.

There was a main effect of Prime on reading time, $\mathrm{F}(1,16)=14.6, \mathrm{p}<.01, \eta_{\mathrm{p}}{ }^{2}=.48$, with narrators in the helpful condition taking longer than narrators in the unhelpful condition. There was no effect of Retelling and no interaction, Fs $<1$ (as expected, given that narrators found out their retelling condition after reading the story). There was also a main effect of Prime on the quality of the narrator's story, $\mathrm{F}(1,16)=17.8, \mathrm{p}<.001, \mathrm{\eta}_{\mathrm{p}}{ }^{2}=.53$, with narrators retelling the story more accurately in the helpful condition than the unhelpful condition, but no effect of Retelling and no interaction, all Fs $<2.5$. Simple main effects of Prime for each level of Retelling revealed a marginal difference between the helpful and unhelpful conditions for the face-to-face condition, $\mathrm{F}(1,16)=3.48, \mathrm{p}=.08, \mathrm{\eta}_{\mathrm{p}}{ }^{2}=.18$, and a significant difference between the helpful and unhelpful condition for the microphone condition, $F(1,16)=16.84, p<.01, \eta_{p}{ }^{2}=.51$. In both the face-to-face and microphone conditions the narrator's story was rated higher when he or she had been primed with the helpful condition. Note that no participants in the face-to-face condition produced verbal feedback to the narrator about the story. (There was some non-verbal feedback such as nodding and laughing but this was not quantified.) The questionnaire responses revealed that although nine of the participants felt that the two parts of the study could be connected, no one pointed to any relationship between the words in the puzzle and their behavior in the story task. Therefore, we assume that priming effects occurred without awareness. 
Hence, priming affected the time taken by the narrator and the quality of the narrator's retelling. To explore the relationship between Prime, reading time, and story quality, we conducted a mediation analysis where Prime and Narrator reading time were entered into a bootstrap analysis predicting Narrator Story quality (Hayes, 2013). Bootstrapping is a statistical resampling method that estimates the indirect effect of an independent variable on a dependent variable via a mediating variable and has been recommended for mediation analyses with small sample sizes (Shrout \& Bolger, 2002). In addition, all variables were transformed into z-scores in order to arrive at standardized coefficients. Figure 1 illustrates the direct effects of all variables. Although there was no direct effect of Narrator reading time on Narrator story quality, there was an effect of Prime on Narrator story quality: Participants who were in the Helpful condition produces higher quality stories. The bootstrap analysis demonstrated that Prime did not have an indirect effect on Narrator story quality via the mediator of Narrator reading time $(B=-0.05, S E$ $=0.09 ; \mathrm{CI}[-0.34,0.03])$.

Addressee Retelling. We conducted a $2 \times 2$ between-subjects ANOVA on the quality of the addressee's story (see Table 2). There were no main effects or interaction (all ps > .28).

These results suggest that nonconscious priming was effective in enhancing the narrator's helpfulness in two ways. The narrator appears to be helpful by spending more time reading the original story, but more importantly, the narrator was also more helpful towards the addressee by producing a better quality story. The retelling condition had no effect on priming: There was no indication that the presence of the addressee affected activation of the narrator's goal concept. Finally, despite the narrator in the helpful condition producing a better retelling of the story, the addressee's subsequent retelling was unaffected by condition.

\section{Experiment 2}


In Experiment 2, we investigated whether priming affects the quality of a written retelling of the story. Because of this, we did not include a face-to-face condition. This experiment used a confederate addressee, purely to make the purpose of retelling apparent to the narrator. If nonconscious priming of helpfulness has a general effect on retelling, it should play a similar role in written narration as it did in spoken narration.

\section{Method}

Forty additional participants (20 female) from the same population as Experiment 1 were paid to take part. The materials (for both tasks) were the same as Experiment 1. The procedure was the same as Experiment 1, except that each participant was assigned the role of narrator and was paired with one of two confederates, who served as the addressee. The confederate was the same sex as the participant, and the participant was unaware that role assignment was not random and that the confederate was not a real participant. The narrator was provided with two sheets of paper and a pen. While the narrator was reading the story, the addressee remained in the room behind a screen and completed other word search puzzles (so that the addressee appeared to play a similar role to the narrator, and hence to be a naïve participant rather than a confederate). The experimenter left the room while the narrator retold the story. The questionnaire and rating procedures were as in Experiment 1, with the written retellings being transcribed and then rated as in Experiment 1. The raters' reliability was .80 (intraclass correlation); we report their mean ratings.

\section{Results and Discussion}

Independent $t$-tests revealed that participants spent longer reading the story in the helpful condition than the unhelpful condition, $\mathrm{t}(38)=11.65, \mathrm{p}<.001$, and wrote higher-quality retellings in the helpful than the unhelpful condition, $t(38)=7.72, \mathrm{p}<.001$ (see Table 2). This 
experiment therefore showed that nonconscious priming was effective in enhancing a written narrator's helpfulness. The questionnaire responses revealed that none of the participants pointed to any relationship between the words in the puzzle and their behavior in the story task. 


\section{General Discussion}

Both experiments replicated findings on implicit goal pursuit and extended them to the important domain of interpersonal communication. They revealed that narrators were nonconsciously primed to be helpful to an addressee whose comprehension depended on the quality of the narration. Participants took longer to read a story and produced better retellings when they had been primed with words associated with helpfulness than when they had been primed with words associated with unhelpfulness. We found similar results whether participants spoke or wrote their retellings. In the spoken retelling, the presence of an addressee that could provide feedback to the narrator had no effect on priming. Our experiments demonstrate that priming people with the concept of helpfulness can affect communicative effectiveness.

We propose that the activation of the concept of helpfulness causes speakers to pay more attention to the needs of the addressees. In other words, they are more concerned about audience design when constructing their utterances (Clark, 1996). This means that priming the concept of helpfulness affects the processes involved in language production (Levelt, 1989). Specifically, such priming causes the narrator to increase attention to understanding and remembering the story, and therefore to spend more time doing so. It also causes the narrator to produce a higherquality retelling of the story. These factors relate to the process of conceptualization, the first stage in language production. But it is possible that priming may also affect processes related to the later stages of language production, such as those concerned with putting the concepts into linguistic form (formulation). For example, priming helpfulness might lead to ambiguity avoidance (Brennan \& Clark, 1996; Haywood et al., 2005), or alternatively to pronounce words more clearly (e.g., Bard et al., 2000). 
Our findings therefore demonstrate a new form of social "nudge" (Thaler \& Sunstein, 2008) that may be practically relevant to situations where helpfulness cues could facilitate successful communication. Such "nudges" constitute ways of changing behavior without explicit instruction or coercion (e.g., encouraging healthy eating by placing healthy foods at eye level in a canteen). Nonconscious priming can be seen as a form of nudge, and so it may be possible to use priming of communicative helpfulness to nudge instructors toward more effective teaching or workplace training. In these cases, the need for helpfulness is apparent but their goals (the extent to which they care about being as helpful as possible) may vary. It may also nudge designers toward more effective road signs or workplace notices, where providing sufficient information may prevent readers going to the wrong location or failing to understand safety procedures. In these cases, the designers may already have helpfulness goals, but they may also not be concerned about communicative effectiveness (they may write the signs or notices without considering whether others are likely to understand them). But as well as having some practical relevance, our findings are important for both social psychological and psycholinguistic theory, two areas of psychology that are concerned with communication but which have tended to be largely independent on each other. 


\section{References}

Aarts, H., Custers, R., \& Marien, H. (2008). Preparing and motivating behavior outside of awareness. Science, 319(5870), 1639.

Aarts, H., Gollwitzer, P. M., \& Hassin, R. R. (2004). Goal contagion: Perceiving is for pursuing. Journal of Personality and Social Psychology, 87, 23-37.

Bandura, A. (1986). Social foundations of thought and action: A social cognitive theory. Upper Saddle River, NJ: Prentice-Hall.

Bard, E. G., Anderson, A. H., Sotillo, C., Aylett, M., Doherty-Sneddon, G., \& Newlands, A. (2000). Controlling the intelligibility of referring expressions in dialogue. Journal of Memory and Language, 42, 1-22.

Bargh, J. A., Gollwitzer, P. M., Lee-Chai, A. Y., Barndollar, K., \& Troetschel, R. (2001). The automated will: Nonconscious activation and pursuit of behavioral goals. Journal of Personality and Social Psychology, 81, 1014-1027.

Bortfeld, H., \& Brennan, S. E. (1997). Use and acquisition of idiomatic expressions in referring by native and non-native speakers. Discourse Processes, 23, 119-147.

Brennan, S. E., \& Clark, H. H. (1996). Conceptual pacts and lexical choice in conversation. Journal of Experimental Psychology: Learning, Memory, and Cognition, 22, 1482-1493.

Chartrand, T. L., \& Bargh, J. A. (1996). Automatic activation of impression formation and memorization goals: Nonconscious goal priming reproduces effects of explicit task instructions. Journal of Personality and Social Psychology, 71, 464-478. 
Chen, S., Lee-Chai, A. Y., \& Bargh, J. A. (2001). Relationship orientation as a moderator of the effects of social power. Journal of Personality and Social Psychology, 80, 173.

Clark, H. H. (1996) Using language. Cambridge University Press.

Clark, M. S., \& Mills, J. (1979). Interpersonal attraction in exchange and communal relationships. Journal of Personality and Social Psychology, 37, 12-24.

Deci, E. L., \& Ryan, R. M. (1985). The general causality orientations scale: Self-determination in personality. Journal of Research in Personality, 19, 109-134.

Dijksterhuis, A., \& Aarts, H. (2010). Goals, attention, and (un) consciousness. Annual Review of Psychology, 61, 467-490.

Dijksterhuis, A., Chartrand, T. L., \& Aarts, H. (2007). Effects of priming and perception on social behavior and goal pursuit. In J. A. Bargh (Ed.), Social psychology and the unconscious: The automaticity of higher mental processes (pp. 51-132). Philadelphia: Psychology Press.

Ferreira, V. S., \& Dell, G. S. (2000). Effect of ambiguity and lexical availability on syntactic and lexical production. Cognitive Psychology, 40, 296-340.

Fussell, S. R., \& Krauss, R. M. (1992). Coordination of knowledge in communication: Effects of speakers' assumptions about what others know. Journal of Personality and Social Psychology, 62, 378-391. 
Glucksberg, S., Krauss, R. M., \& Weisberg, R. (1966). Referential communication in nursery school children: Method and some preliminary findings. Journal of Experimental Child Psychology, 3, 333-342.

Grice, H. P. (1957). Meaning. The Philosophical Review, 66, 377-88.

Grice, P. (1975). Logic and conversation. In P. Cole, P., \& J. Morgan (Eds), Syntax and semantics (Vol. 3, Speech acts, pp. 41-58). New York: Academic Press.

Hayes, A. F. (2013). Introduction to mediation, moderation, and conditional process analysis. New York: The Guilford Press.

Haywood, S. L., Pickering, M. J., \& Branigan, H. P. (2005). Do speakers avoid ambiguities during dialogue? Psychological Science, 16, 362-366.

Horton, W. S., \& Gerrig, R. J. (2002). Speakers' experiences and audience design: Knowing when and knowing how to adjust utterances to addressees. Journal of Memory and Language, 47, 589-606.

Horton, W. S., \& Keysar, B. (1996). When do speakers take into account common ground? Cognition, 59, 91-117.

Isaacs, E. A., \& Clark, H. H. (1987). References in conversation between experts and novices. Journal of Experimental Psychology: General, 116, 26-37.

Levelt, W.J.M. (1989). Speaking: From intention to articulation. Cambridge, MA: MIT Press.

Locke, E. A., \& Latham, G. P. (2006). New directions in goal-setting theory. Current Directions in Psychological Science, 15, 265-268. 
Moskowitz, G. B., Gollwitzer, P. M., Wasel, W., \& Schaal, B. (1999). Preconscious control of stereotype activation through chronic egalitarian goals. Journal of Personality and Social Psychology, 77, 167-184.

Moskowitz, G.B., \& Li, P. (2011). Egalitarian goals trigger stereotype inhibition: A proactive form of stereotype control. Journal of Experimental Social Psychology, 47, 103-116.

Moskowitz, G. B., Li, P., \& Kirk, E. R. (2004). The Implicit Volition Model: On the Preconscious Regulation of Temporarily Adopted Goals. In M. P. Zanna, (Ed), Advances in experimental social psychology (Vol. 36, pp. 317-413). San Diego, CA: Academic Press.

Over, H., \& Carpenter, M. (2009). Eighteen-month-old infants show increased helping following priming with affiliation. Psychological Science, 20, 1189-1193.

Ratcliff, R. \& McKoon, G. (1988). A retrieval theory of priming in memory. Psychological Review, 95, 385-408.

Shrout, P. E., \& Bolger, N. (2002). Mediation in experimental and nonexperimental studies: New procedures and recommendations. Psychological Methods, 7(4), 422-445.

Thaler, R. H., \& Sunstein, C. R. (2008). Nudge: Improving decisions about health, wealth, and happiness. Yale University Press.

Thompson, E. P., Roman, R. J., Moskowitz, G. B., Chaiken, S., \& Bargh, J. A. (1994). Accuracy motivation attenuates covert priming effects: The systematic reprocessing of social information. Journal of Personality and Social Psychology, 66, 474-489. 
Table 1

Mean (and standard deviation of) reading time (in seconds) by condition in Experiments 1 and 2.

\begin{tabular}{|c|l|l|l|}
\hline Experiment & Prime & Retelling & Reading Time \\
\hline $\mathbf{1}$ & helpful & face-to-face & $264(53)$ \\
& & microphone & $216(109)$ \\
& unhelpful & face-to-face & $108(50)$ \\
& & microphone & $132(50)$ \\
\hline $\mathbf{2}$ & helpful & written & $245(48)$ \\
& unhelpful & written & $119(22)$ \\
\hline
\end{tabular}


Table 2

Mean (and standard deviation) of ratings for the story retelling by condition and participant in Experiments 1 and 2

\begin{tabular}{|c|c|c|c|c|}
\hline Experiment & Participant & Prime & Retelling & Rating \\
\hline 1 & $\begin{array}{l}\text { narrator } \\
\text { addressee }\end{array}$ & $\begin{array}{l}\text { helpful } \\
\text { unhelpful } \\
\text { helpful } \\
\text { unhelpful }\end{array}$ & $\begin{array}{l}\text { face-to-face } \\
\text { microphone } \\
\text { face-to-face } \\
\text { microphone } \\
\text { face-to-face } \\
\text { microphone } \\
\text { face-to-face } \\
\text { microphone }\end{array}$ & $\begin{array}{l}4.00(1.17) \\
4.30(0.67) \\
3.00(0.61) \\
2.10(0.82) \\
2.20(0.34) \\
2.30(0.25) \\
2.30(0.37) \\
1.70(0.25)\end{array}$ \\
\hline 2 & narrator & $\begin{array}{l}\text { helpful } \\
\text { unhelpful }\end{array}$ & $\begin{array}{l}\text { written } \\
\text { written }\end{array}$ & $\begin{array}{l}4.35(0.61) \\
2.45(0.91)\end{array}$ \\
\hline
\end{tabular}


Figure 1

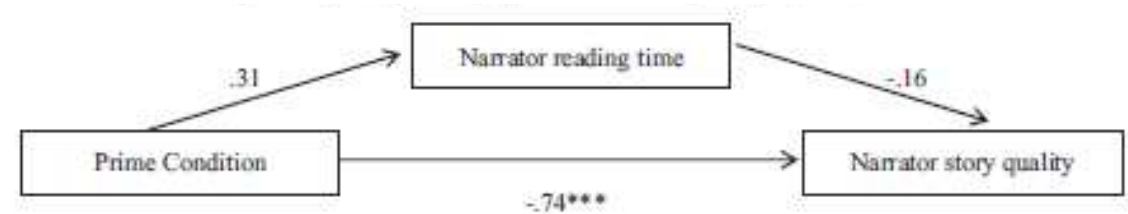

Fig. 1. Standardived regressioncoeflicients for die felarionship between Prime and Narrator stary quality as medisted ty Narratar reading time 